\title{
Catalysis and evolution on cycling of nano-structured magnesium multilayer thin films
}

\author{
Christopher M. P. Fry ${ }^{\mathrm{a}, *}$, David M. Grant ${ }^{\mathrm{b}}$, Gavin S. Walker ${ }^{\mathrm{b}}$ \\ ${ }^{a}$ Materials, Mechanics and Structures Research Division, Faculty of Engineering, University of \\ Nottingham, University Park, Nottingham NG7 2RD, UK \\ ${ }^{b}$ Energy and Sustainability Research Division, Faculty of Engineering, University of Nottingham, \\ University Park, Nottingham NG7 2RD, UK
}

\begin{abstract}
This paper explores the hydrogen cycling properties of $\mathrm{Mg} / \mathrm{Cr}$ and $\mathrm{Mg} / \mathrm{V}$ multilayer thin films and studies the effect of chromium and vanadium transition metal catalysts on the cycling properties of thick magnesium coatings. Two transition-metal catalysed magnesium-based multilayer PVD coatings are compared with a non-catalysed magnesium control sample. The (micro-)structural evolution of the thin film coatings into fine, flakey powders is studied in-depth using XRD, SEM and TEM and the hydrogen storage properties of all three materials are assessed using volumetric, gravimetric and calorimetric methods focussing on the effect of the microstructure and composition of the coatings on the hydrogen storage kinetics. It was found that the chromiumcatalysed coating had the most favourable hydrogen storage kinetics with an activation energy for the dehydrogenation reaction of $65.7 \pm 2.5 \mathrm{~kJ} \mathrm{~mol}^{-1}$ and a hydrogen capacity of $6.1 \pm 0.3 \mathrm{wt} \%$. The mechanism of the dehydrogenation reaction of the catalysed samples was studied using the CV and JMAK kinetic models and it was found that the catalyst material influenced not only the hydrogen storage kinetics but also the mechanism of the reaction.
\end{abstract}

Keywords: Hydrogen storage, Magnesium, Thin film, Chromium, Vanadium, multilayer

\section{Introduction}

Hydrogen is a versatile energy carrier that has applications ranging from consumer electronics to heavy-duty machinery. Its aggregate state and density at ambient conditions however make efficiently storing large quantities of hydrogen in a small volume challenging. Unlike compression and liquefaction of hydrogen, solid-state hydrogen storage can offer a cost- and energy efficient way of storing large amounts of hydrogen.

\footnotetext{
${ }^{*}$ Corresponding author. Tel.: +441159513747

Email addresses: Christopher.Fry@alumni .nottingham.ac.uk (Christopher M. P. Fry), David.Grant@nottingham.ac.uk (David M. Grant), Gavin. Walker@nottingham.ac.uk (Gavin S. Walker)
} 
Magnesium hydride is both relatively cheap and abundant and together with its high gravimetric and volumetric hydrogen storage capacity of $7.7 \mathrm{wt} \%$ and $0.11 \mathrm{~kg} \mathrm{H}_{2} \mathrm{l}^{-1} \mathrm{re}-$ spectively that makes it a favoured material for practical applications. Overcoming the challenging thermodynamic and kinetic limitations of the material, requiring temperatures above $300^{\circ} \mathrm{C}$ in practice, has been the focus of a wide range of research activity. Many attempts have been made to reduce the temperatures required to reversibly store hydrogen in magnesium-based materials including the addition of transition metals and their oxides to form catalysed structures resulting in faster kinetics at lower temperatures including a range of systems using thin film techniques to incorporate these catalysts into the magnesium-based material. Examples include systems of $\mathrm{Mg}-\mathrm{Pd}$ $[1,2] \mathrm{Mg}-\mathrm{Ti}[3,4]$ and $\mathrm{Mg}-\mathrm{Ni}[5,6]$. Previous work [7] has shown improved kinetics for a magnesium-based multilayer system catalysed by a nickel-rich transition metal mix. Alloying of magnesium and nickel leads to a two-phase hydrogen storage system of $\mathrm{MgH}_{2}$ and $\mathrm{Mg}_{2} \mathrm{NiH}_{4}$ catalysed by transition metal elements such as chromium and iron. This work investigates the effect of chromium and vanadium on the kinetics of magnesium multilayer thin films.

\section{Experimental Methods}

A Teer Coatings UDP 650 closed field unbalanced magnetron-assisted physical vapour deposition (PVD) system, based on an argon plasma, was used to produce a range of different thin film multilayer coatings, consisting of layers of magnesium (purity $99.9 \%)$, separated by layers of chromium $(\mathrm{Mg} / \mathrm{Cr})$ and vanadium $(\mathrm{Mg} / \mathrm{V})$ transition metal catalysts (target purity $99.95 \%$ ), and capped on both surfaces with a thin $(14 \mathrm{~nm})$ layer of palladium (target purity $99.99 \%$ ) to prevent oxidation of the thin film and interaction with the substrate. In order to try and prevent any MgPd alloy formation as described by Tan et al. [4], a transition metal layer was deposited on the inside of both $\mathrm{Pd}$ capping layers. In addition, a magnesium control sample $\left(\mathrm{Mg}_{\text {control }}\right)$ was produced by depositing 150 layers of magnesium, under the same processing conditions used for the $\mathrm{Mg} / \mathrm{Cr}$ and $\mathrm{Mg} / \mathrm{V}$ samples, without transition metal interlayers, capped with $14 \mathrm{~nm}$ of Pd on both sides.

The PVD system enabled large surface areas to be coated generating ca. $300 \mathrm{mg}$ of coatings that were delaminated from the glass substrates in acetone post deposition. $150-190 \mathrm{mg}$ of each of the samples was then cycled up 60 times in a Setaram PCTpro sievert apparatus at selected temperatures between $250^{\circ} \mathrm{C}$ and $350^{\circ} \mathrm{C}$ under hydrogen pressures up to $2 \mathrm{MPa}$ in order to study the kinetic behaviour and structural changes of the material.

The microstructure of the thin films was assessed both before and after hydrogen cycling by X-ray diffraction (XRD) on a Bruker D8 Advance diffractometer emitting

monochromated $\mathrm{CuK} \alpha$ radiation with a wavelength $\lambda$ of $1.5418 \AA$ through a $0.6 \mathrm{~mm}$ slit at $40 \mathrm{kV}$ and $40 \mathrm{~mA}$, in a Bragg-Brentano $\theta-2 \theta$ configuration. A series of lockedcoupled $\theta-2 \theta$ scans were performed with a step size fixed at $0.05^{\circ}$ a dwell time of $5 \mathrm{~s}$ per step for the as-deposited thin films and step size of $0.03^{\circ}$ a dwell time of $10 \mathrm{~s}$ per step for the samples post cycling. For peak broadening analysis instrumental broadening was determined using a $\mathrm{LaB}_{6}$ reference sample. 
Scanning electron microscopy (SEM) and energy-dispersive X-ray spectroscopy (EDX) analysis was done on a high resolution Philips XL30 ESEM-FEG with an Oxford Instruments silicon drift EDX detector to determine the composition and overall layer thickness of the coatings' cross-sections, as well as the morphology of the thin films post-cycling. Transmission electron microscopy (TEM) and EDX analysis was performed on a JEOL 2100F (post cycling) microscope fitted with an Oxford Instruments INCA EDX system. The TEM sample preparation was done by suspending a small amount of the powder in acetone and pipetting a drop of the suspension onto a holey carbon grid. The same microscope was used to produce cross-sectional TEM image of the as-deposited $\mathrm{Mg} / \mathrm{Cr}$ sample following sample preparation on a FEI Quanta200 FIB/SEM. A Philips Tecnai F20 microscope was used to analyse the cross-section of the as-deposited $\mathrm{Mg} / \mathrm{V}$ sample, a lift-out of which was prepared using a FEI Quanta3D FIB/SEM.

The dehydrogenation reaction of the sample was studied using differential scanning calorimetry (DSC) (Netzsch 204HP) using heating rates of $2^{\circ} \mathrm{C} \min ^{-1}, 5^{\circ} \mathrm{C} \mathrm{min}^{-1}$ and $10^{\circ} \mathrm{C} \mathrm{min}^{-1}$ under $0.1 \mathrm{MPa}$ of flowing Ar at a rate of $100 \mathrm{ml} \mathrm{min}^{-1}$. A Netzsch 209 F1 Iris thermobalance was used for thermogravimetric analysis (TGA) of the samples under a flow of $100 \mathrm{ml} \mathrm{min}^{-1}$ of argon at atmospheric pressure, using a heating rate of $10^{\circ} \mathrm{C} \mathrm{min}{ }^{-1}$ from room temperature to up to $500^{\circ} \mathrm{C}$.

\section{Results}

\subsection{Structural Analysis}

The results of the X-ray diffraction study undertaken on the as-deposited thin film coatings are presented in figure 1. It is evident from the diffraction patterns that there is strong directional growth of HCP Mg-crystals in the $<001>$ direction in all samples, indicated by diffraction peaks only in the (002) and (004) planes at 34.4 and $72.5^{\circ} 2 \theta$ and there are peaks coming from the (111) planes from the palladium capping layers at $40.1^{\circ} 2 \theta$. In none of the samples is there any evidence of crystalline catalyst phases.

Similarly, figure 2 shows diffraction patterns taken for the three thin film samples in their hydrogenated state after 60 cycles of hydrogenation and dehydrogenation. It is clearly visible that the samples have all undergone similar changes in their microstructure, evident by the emergence of $\beta$-magnesium hydride and $\mathrm{Mg}_{6} \mathrm{Pd}$ phases in all three samples. In the two catalysed samples there is also evidence of crystalline phases of BCC chromium $(\mathrm{Mg} / \mathrm{Cr})$ and $\mathrm{BCC}$ vanadium $(\mathrm{Mg} / \mathrm{V})$ and all three samples exhibit traces of unreacted magnesium as well as magnesium oxide. The latter is likely to have been formed during handling of the thin film samples in air during delamination from the substrate.

SEM analysis (not shown) revealed that the overall thickness of the coatings is 2.74, 2.60 and $2.50 \mu \mathrm{m}$ for the $\mathrm{Mg} / \mathrm{Cr}, \mathrm{Mg} / \mathrm{V}$ and $\mathrm{Mg}_{\text {control }}$ samples respectively which translates into ca. 18.3 and $17.3 \mathrm{~nm}$ per bi-layer in the 150 multilayer $\mathrm{Mg} / \mathrm{Cr}$ and $\mathrm{Mg} / \mathrm{V}$ structures. The composition of the catalysed samples was studied using EDX and it was found that the $\mathrm{Mg} / \mathrm{Cr}$ sample contained $3.3 \pm 0.1 \mathrm{wt} \%$ chromium whilst the $\mathrm{Mg} / \mathrm{V}$ sample contained $5.2 \pm 0.2 \mathrm{wt} \%$ vanadium. The diffraction patterns for the as deposited samples shown in figure 1 exhibits broad peaks indicative of a small crystallite size. 


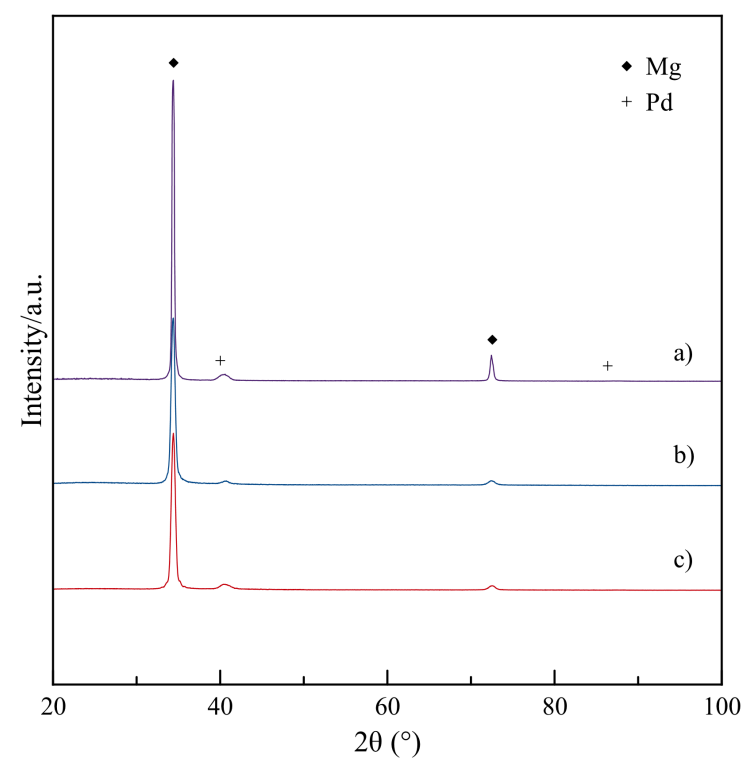

Figure 1: XRD pattern of the a) $\mathrm{Mg}_{\text {control }}$, b) $\mathrm{Mg} / \mathrm{V}$ and c) $\mathrm{Mg} / \mathrm{Cr}$ thin films in their as-deposited state

Using Scherrer's equation [8] an estimate of the grain size of the magnesium phase in each multilayer sample was derived from the full width of the (002) and (004) peaks at half their maximum intensity (FWHM). Average values of $17 \pm 3,16 \pm 3 \mathrm{~nm}$ and $50 \pm 3 \mathrm{~nm}$ were obtained for the $\mathrm{Mg} / \mathrm{Cr}, \mathrm{Mg} / \mathrm{V}$ and $\mathrm{Mg}_{\text {control }}$ samples respectively. Similarly, the grain size of the magnesium hydride phase in the hydrogenated powders was estimated at $136 \pm 50 \mathrm{~nm}$ and $100 \pm 39 \mathrm{~nm}$ for the $\mathrm{Mg} / \mathrm{Cr}$ and $\mathrm{Mg} / \mathrm{V}$ samples respectively using the Williamson-Hall method [9]. The $\mathrm{Mg}_{\text {control }}$ sample's diffraction peaks in contrast were too sharp to extract any information about the grain size of the hydride phase. Using Scherrer's equation, the grain size of the chromium phase was established from the peak broadening of the X-ray signal. The chromium phase in the hydrogenated $\mathrm{Mg} / \mathrm{Cr}$ powder has a measured grain size of $20 \pm 5 \mathrm{~nm}$. The vanadium phase in the hydrogenated $\mathrm{Mg} / \mathrm{V}$ powder, confirmed by TEM, was too convoluted with neighbouring peaks to allow a measurement of peak broadening.

The TEM images in figure 3 confirm the presence of 150 bi-layers in both catalysed thin films with alternating $\mathrm{Mg}$ and catalyst layers, as expected from the coating conditions. High-resolution TEM images such as the ones presented in figures $3 \mathrm{~b}$ and $3 \mathrm{~d}$ were used to measure the thickness of the Mg layers at ca. $18 \pm 0.1$ and $17 \pm 0.1$ $\mathrm{nm} / \mathrm{layer}$ for the $\mathrm{Mg} / \mathrm{Cr}$ and $\mathrm{Mg} / \mathrm{V}$ coatings respectively, and that of the transition metal interlayers at ca. $0.8 \pm 0.1 \mathrm{~nm} /$ layer for the chromium layers and $1.2 \pm 0.1 \mathrm{~nm} / \mathrm{layer}$ for the vanadium layers.

Lattice fringes in the high-resolution TEM image shown in figure $3 \mathrm{~d}$ had a mea- 


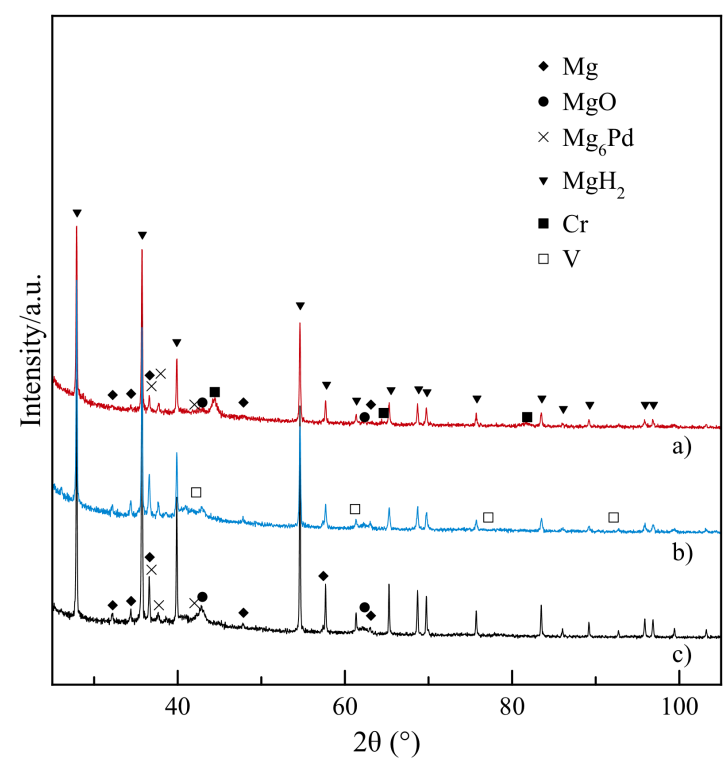

Figure 2: XRD pattern of the a) $\mathrm{Mg} / \mathrm{Cr}$, b) $\mathrm{Mg} / \mathrm{V}$ and c) $\mathrm{Mg}_{\text {control }}$ thin films in their hydrogenated state after 60 cycles of hydrogenation and dehydrogenation

sured spacing of $2.61 \pm 0.03 \AA$ and $1.94 \pm 0.03 \AA$ which correspond to database values of 2.605 and $1.900 \AA$ for planes of $\mathrm{Mg}(002)$ and $\mathrm{Mg}(102)$. The image shows the crystal structure is interrupted at the interface with the vanadium layers which show no evidence of crystallinity.

The EDX maps in figure 4 were taken from the area presented in the STEM inlay in figure $3 \mathrm{a}$, showing the X-ray signal corresponding to the elemental magnesium, chromium and palladium present in the sample.

The high temperatures and repeated hydrogen cycling at temperatures between $250^{\circ} \mathrm{C}$ and $350^{\circ} \mathrm{C}$ changed the physical appearance of the thin film samples. The asdeposited, delaminated thin film flakes of shiny metallic appearance that were used for the cycling experiments disintegrated into fine, grey, flaky powders. The TEM images in figure 5 show an $\mathrm{Mg} / \mathrm{Cr}$ particle which is sufficiently small to allow the transmission of electrons in TEM. The particle exhibits a heterogeneous distribution of dark, circular features throughout the bulk of the material, which produce diffraction patterns that can be indexed to BCC chromium as shown in figure 5a as well as a series of rings corresponding to the diffraction pattern of magnesium oxide. Figure $5 \mathrm{~b}$ shows a high-resolution TEM image of one of these dark features. The feature produces lattice fringes with a d-spacing of $2.05 \pm 0.03 \AA$ which matched the database d-spacing of BCC chromium (110) planes of $2.039 \AA$ A. Similarly the image exhibits lattice fringes coming from the surrounding material which corresponds to the (002) planes of magnesium oxide $(\mathrm{d}=2.106 \AA)$ with a measured d-spacing of $2.14 \pm 0.03 \AA$. 


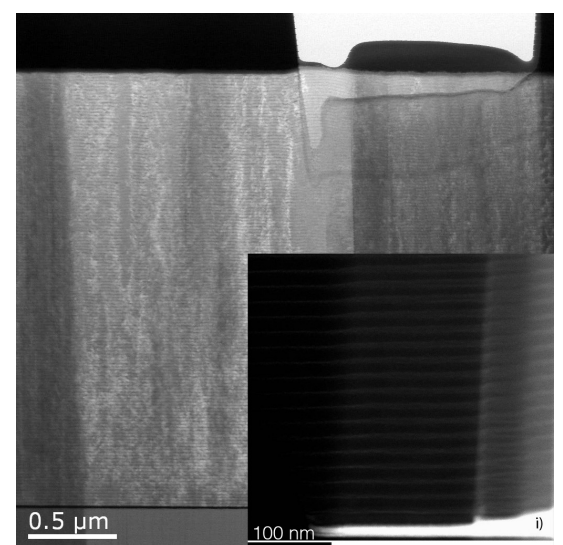

(a)

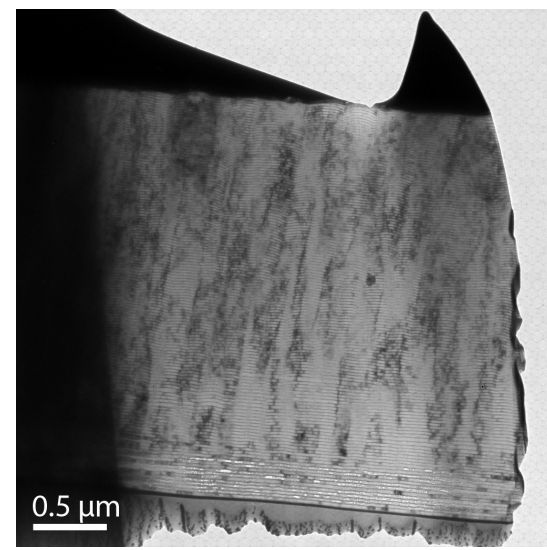

(c)

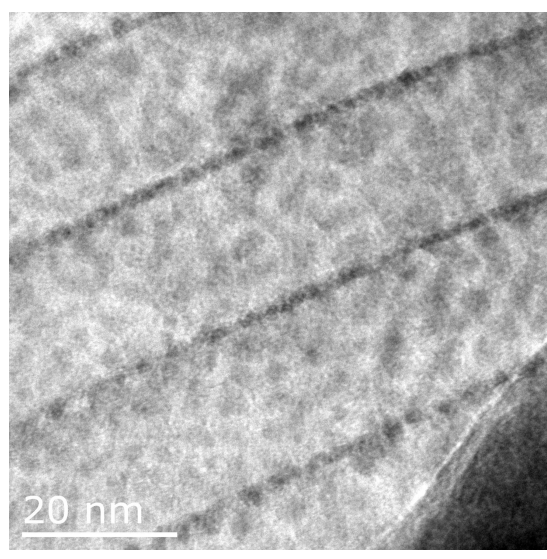

(b)

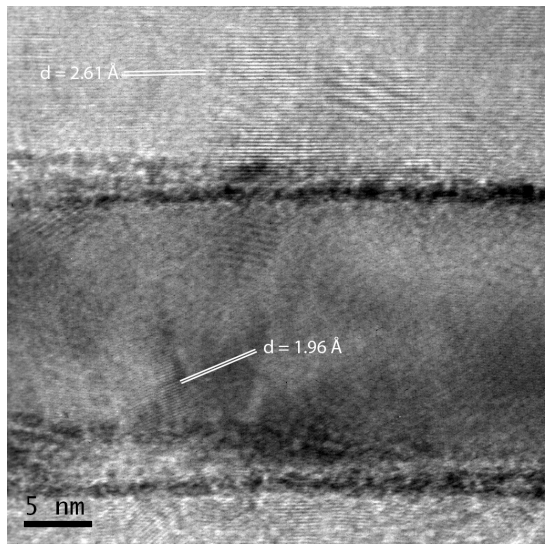

(d)

Figure 3: TEM images of the as-deposited $\mathrm{Mg} / \mathrm{Cr}$ and $\mathrm{Mg} / \mathrm{V}$ multilayer samples showing a) the overall structure of the $\mathrm{Mg} / \mathrm{Cr}$ multilayer with i) a STEM image of the bottom 18 bi-layers, b) a high-resolution image of 4 bi-layers located towards the top of the coating, c) an image of the entire $\mathrm{Mg} / \mathrm{V}$ structure and d) a high resolution TEM image of 2 bi-layers from the central part of the coating

The high-angle annular dark field (HAADF) image of the same particle in figure 6a suggests that the dark features seen in figure 5 are of higher atomic number than the surrounding material, evident from their increased brightness. The EDX maps of the magnesium and chromium signal shown in figures $6 \mathrm{~b}$ and $6 \mathrm{c}$ suggest that the areas of high Z-contrast correspond with the EDX signal of chromium.

Figure 7a shows that the hydrogenated $\mathrm{Mg} / \mathrm{V}$ sample powder particles also exhibit a heterogeneous distribution of darker features throughout the bulk of the structure. The high-resolution TEM image in figure $7 \mathrm{~b}$ shows one of these regions which produces 


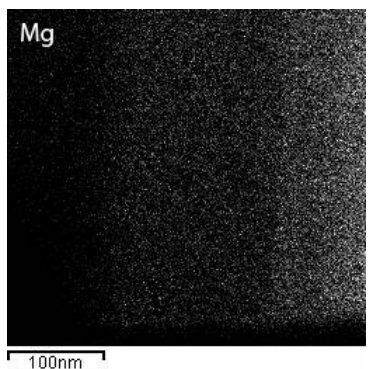

(a)

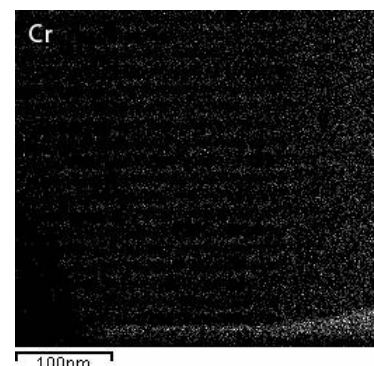

(b)

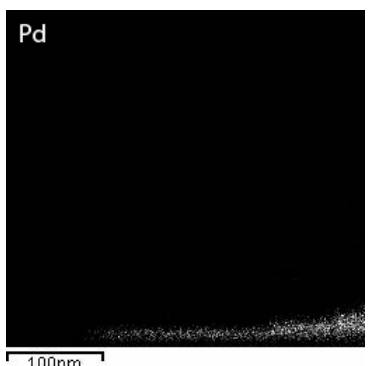

(c)

Figure 4: STEM EDX maps of a selected area of the multilayer structure showing the regional elemental concentration of a) magnesium, b) chromium and c) palladium

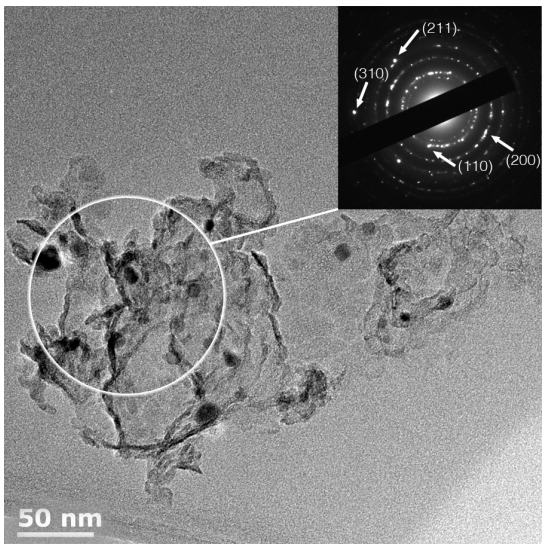

(a)

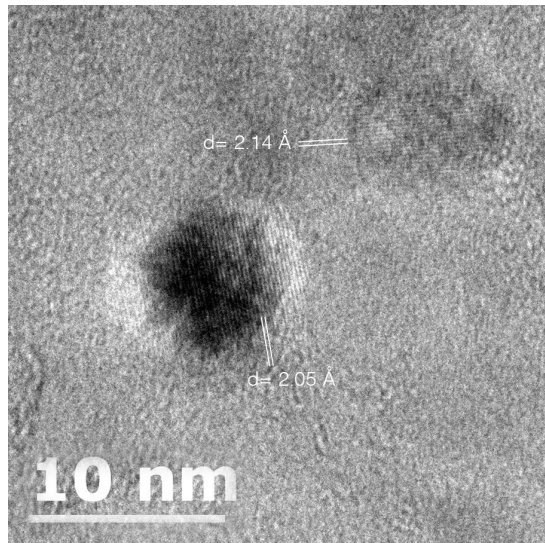

(b)

Figure 5: Bright-field TEM images showing a) an $\mathrm{Mg} / \mathrm{Cr}$ thin film particle in its hydrogenated state after 60 cycles of hydrogenation and dehydrogenation with an SAED pattern from the area highlighted, indexed for chromium and b) lattice fringes in highresolution TEM coming from a dark feature in the sample and the surrounding material

lattice fringes that, with a d-spacing of $2.14 \pm 0.03 \AA$ corresponds to database values for BCC vanadium $(\mathrm{d}=2.141 \AA)$. The SAED pattern overlaid onto figure 7 a confirms this, showing a series of spots corresponding to d-spacings of BCC vanadium as well as magnesium oxide.

The HAADF image shown in figure 8a suggests high Z-contrast coming from the dark features shown in figure 7, which is in agreement with the EDX maps shown in figures $8 \mathrm{~b}$ and $8 \mathrm{c}$, confirming these features contain vanadium. 


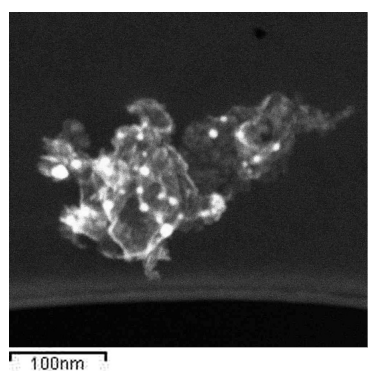

(a)

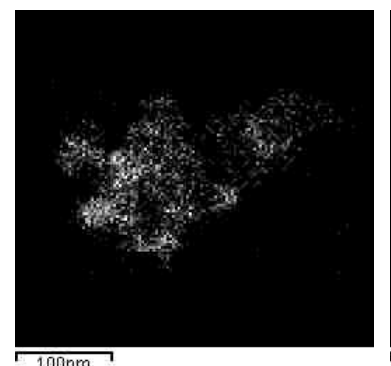

(b)

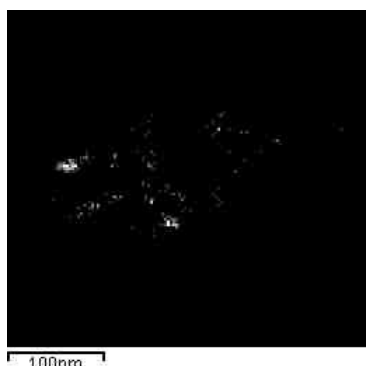

(c)

Figure 6: STEM images showing a) an HAADF image of an $\mathrm{Mg} / \mathrm{Cr}$ particle in its hydrogenated state, b) an EDX map of the magnesium signal coming from the same particle and c) an EDX map of the chromium signal coming from the same particle, showing distinct layers of chromium

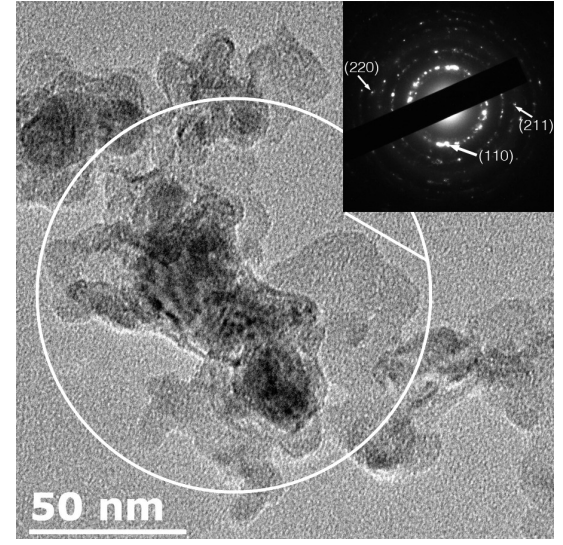

(a)

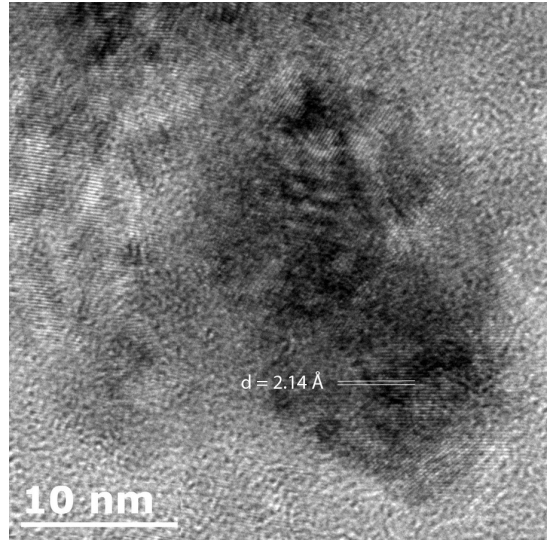

(b)

Figure 7: Bright-field TEM images showing a) an $\mathrm{Mg} / \mathrm{V}$ thin film particle in its hydrogenated state after 60 cycles of hydrogenation and dehydrogenation with an SAED pattern from the area highlighted, indexed for vanadium and b) lattice fringes in highresolution TEM coming from the dark region of the sample and the surrounding material

\subsection{Hydrogen Storage Characteristics}

Figure 9a shows a series of pressure-composition isotherms (PCI) taken for each of the three samples in $20^{\circ} \mathrm{C}$ steps for a range of temperatures between $280^{\circ} \mathrm{C}$ and $320^{\circ} \mathrm{C}$ for the catalysed samples and $310^{\circ} \mathrm{C}$ and $350^{\circ} \mathrm{C}$ for the $\mathrm{Mg}_{\text {control }}$ sample. Figure $9 \mathrm{~b}$ shows the corresponding van't Hoff plots of $\ln (p) v s 1 / T$ where $p$ is the plateau pressure of the midpoints of the dehydrogenation plateaus and $T$ is the corresponding temperature. These plots were used to derive the dehydrogenation enthalpies $(\Delta \mathrm{H})$ and 


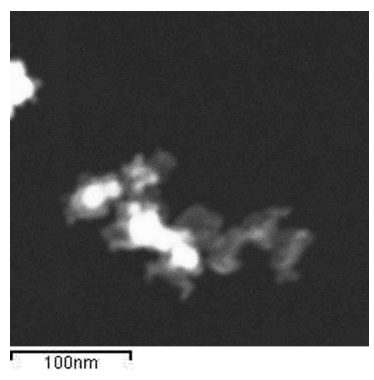

(a)

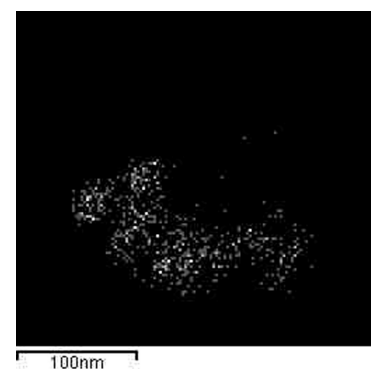

(b)

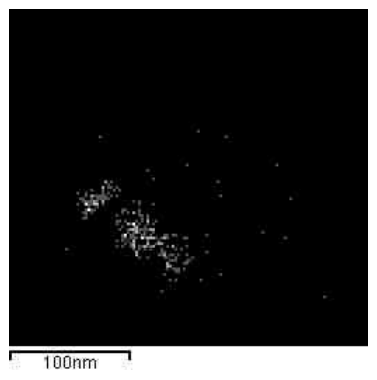

(c)

Figure 8: STEM images showing a) an HAADF image of an $\mathrm{Mg} / \mathrm{V}$ particle in its hydrogenated state, b) an EDX map of the magnesium signal coming from the same particle and c) an EDX map of the vanadium signal coming from the same particle

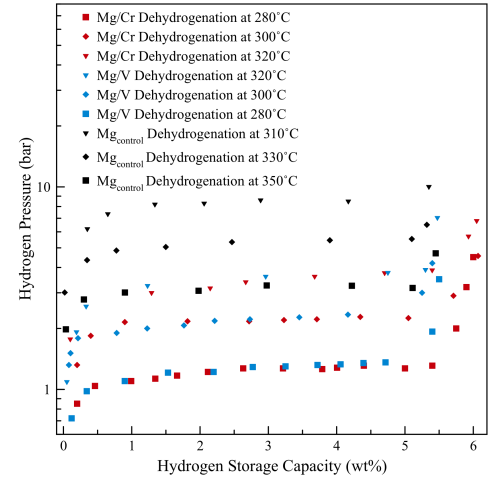

(a)

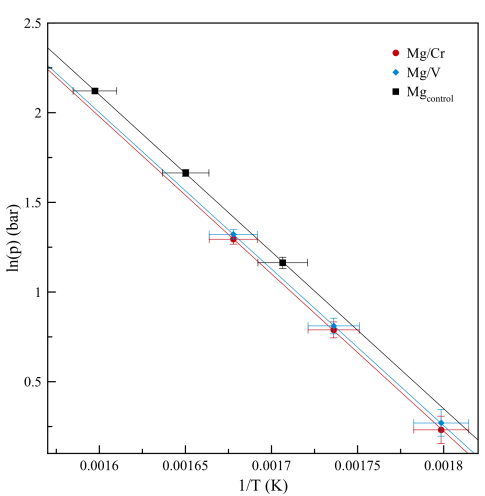

(b)

Figure 9: a) PCI dehydrogenation isotherms taken for the $\mathrm{Mg} / \mathrm{Cr}$ and $\mathrm{Mg} / \mathrm{V}$ samples at 280,300 and $320^{\circ} \mathrm{C}$ and for the $\mathrm{Mg}_{\text {control }}$ sample at 310,330 and $350^{\circ} \mathrm{C}$ and b) corresponding van't Hoff plots

entropies $(\Delta S)$ of the three materials, presented in table 1.

\begin{tabular}{lll} 
Sample & $\Delta \mathrm{H}\left(\mathrm{kJ} \mathrm{mol}^{-1} \mathrm{H}_{2}\right)$ & $\Delta \mathrm{S}\left(\mathrm{J} \mathrm{K}^{-1} \mathrm{~mol}^{-1} \mathrm{H}_{2}\right)$ \\
\hline $\mathrm{Mg} / \mathrm{Cr}$ & $73.6 \pm 0.6$ & $133.7 \pm 1.0$ \\
$\mathrm{Mg} / \mathrm{V}$ & $73.3 \pm 0.3$ & $133.4 \pm 0.5$ \\
$\mathrm{Mg}$ control & $73.9 \pm 0.6$ & $134.8 \pm 0.9$
\end{tabular}

Table 1: Table showing the dehydrogenation enthalpies and entropies of the $\mathrm{Mg} / \mathrm{Cr}$, $\mathrm{Mg} / \mathrm{V}$ and $\mathrm{Mg}_{\text {control }}$ samples 
For each of the samples a series of dehydrogenation experiments were carried out at a range of temperatures between $250^{\circ} \mathrm{C}$ and $320^{\circ} \mathrm{C}$ for the catalysed samples and between $300^{\circ} \mathrm{C}$ and $350^{\circ} \mathrm{C}$ for the $\mathrm{Mg}_{\text {control }}$ sample in order to determine the reaction kinetics of the materials.

The reaction curves of the $\mathrm{Mg} / \mathrm{V}$ and $\mathrm{Mg}_{\text {control }}$ samples in terms of the reacted fraction $\alpha$, the reaction rate $k$, the Avrami exponent $n$, and time $t$ were linearised by double-logarithm fitting of the JMAK model [10] where

$$
\ln \left[\ln \left(\frac{1}{1-\alpha}\right)\right]=n \ln (k)+n \ln (t)
$$

whilst for the $\mathrm{Mg} / \mathrm{Cr}$ the best fit was given with the $\mathrm{CV}_{n=2}$ model [11] where

$$
1-[1-\alpha]^{\frac{1}{2}}=k t .
$$

From the slopes of the linear regression lines of the different materials' kinetic model at each temperature, Arrhenius plots of $\ln k v s 1 / T$ were generated.

The gradients of these Arrhenius plots were used to calculate the activation energy $\left(\mathrm{E}_{a}\right)$ of each reaction from the Arrhenius equation (equation 3)

$$
k=k_{0} e^{-E_{a} / R T} .
$$

Figure 10 shows the Arrhenius plots of the three samples, resulting in the calculated values of activation energy for each sample as tabulated in table 2 .

\begin{tabular}{lc} 
Sample & $\mathrm{E}_{a}\left(\mathrm{~kJ} \mathrm{~mol}^{-1}\right)$ \\
\hline $\mathrm{Mg} / \mathrm{Cr}$ & $69.7 \pm 5.8$ \\
$\mathrm{Mg} / \mathrm{V}$ & $71.1 \pm 5.0$ \\
$\mathrm{Mg}_{\text {control }}$ & $142.9 \pm 5.0$
\end{tabular}

Table 2: Table showing the activation energies of the three samples' dehydrogenation reaction calculated from the Arrhenius plots shown in figure 10

The kinetic curves for the catalysed samples can be seen in figures $11 \mathrm{~b}$ and $12 \mathrm{~b}$, showing an increase in reaction rate with temperature. Figures 11a and 12a show the linearised data which was used to determine $k$ in the case of the $\mathrm{Mg} / \mathrm{Cr}$ sample, and $k$ and $n$ in the case of the $\mathrm{Mg} / \mathrm{V}$ sample. Figure 12a is representative also for the graphs that were produced to determine the activation energy of the $\mathrm{Mg}_{\text {control }}$ sample.

This data was verified using controlled heating of the samples in DSC in conjunction with the Kissinger method [12] which relates the heating rate $\phi$ to the DSC peak temperature $T_{m}$ via the equation

$$
\frac{d\left(\ln \frac{\phi}{T_{m}^{2}}\right)}{d\left(\frac{1}{T_{m}}\right)}=-\frac{E}{R} .
$$

Figure 13a shows a series of DSC plots for the $\mathrm{Mg} / \mathrm{Cr}$ and $\mathrm{Mg} / \mathrm{V}$ samples at heating rates of 2,5 , and $10^{\circ} \mathrm{C} \mathrm{min}{ }^{-1}$. In comparison, figure $13 \mathrm{~b}$ shows a series of endotherms 


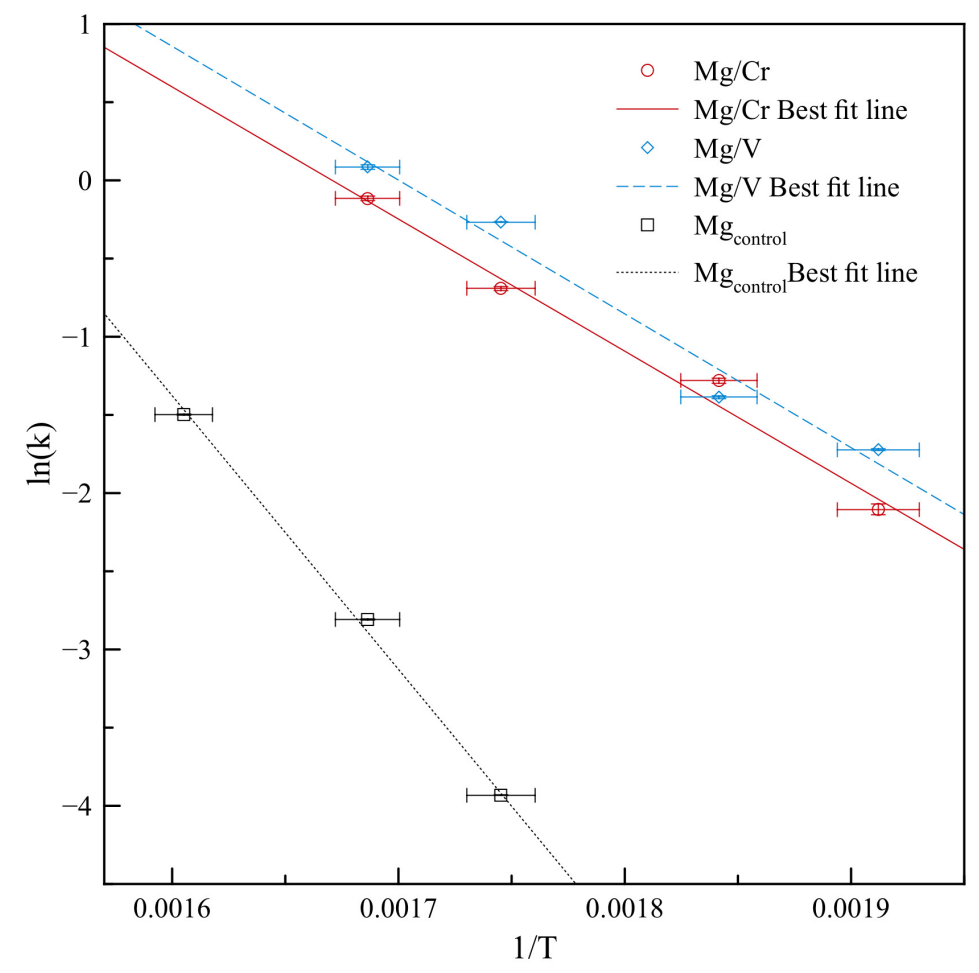

Figure 10: Arrhenius plots showing the linear variation in $\ln k$ with $1 / T$ for the $\mathrm{Mg} / \mathrm{Cr}$ and $\mathrm{Mg} / \mathrm{V}$ samples' reaction rates at $250,270,300$ and $320^{\circ} \mathrm{C}$ and for the $\mathrm{Mg}_{\text {control }}$ sample's reaction rates at 300,320 and $350^{\circ} \mathrm{C}$

measured for the $\mathrm{Mg}_{\text {control }}$ sample.

MagicPlot peak fitting software was used to de-convolute the twin-peak endotherms and establish the peak temperature of each peak. The average peak temperature was calculated from the relative peak area, resulting in an activation energy for the whole reaction, derived from Kissinger plots (not shown) and tabulated in table 3. The table also includes the activation energy calculated from a Kissinger plot generated from DSC endotherms measured for an as-received $\mathrm{MgH}_{2}$ reference sample (Alfa Aesar, 98\% $\mathrm{MgH}_{2}$ ).

The hydrogen storage capacities of each of the materials were measured by volumetric methods during the PCI and kinetic studies. The values, tabulated in table 4 were verified by gravimetric measurements during heating of the samples to $400^{\circ} \mathrm{C}$ $(\mathrm{Mg} / \mathrm{Cr}$ and $\mathrm{Mg} / \mathrm{V})$ and $500^{\circ} \mathrm{C}\left(\mathrm{Mg}_{\text {control }}\right)$ in the TGA and they were found to remain constant over the 60 cycles that the samples underwent. 


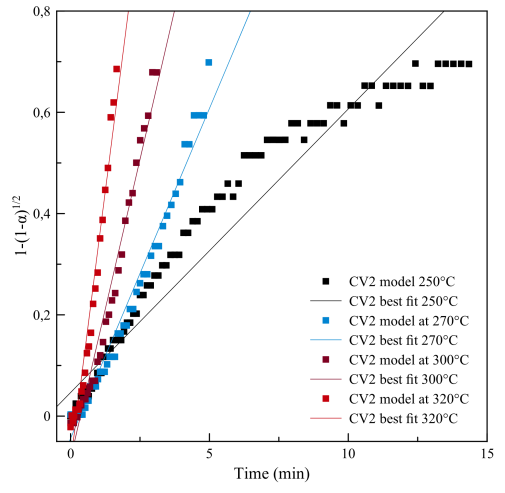

(a)

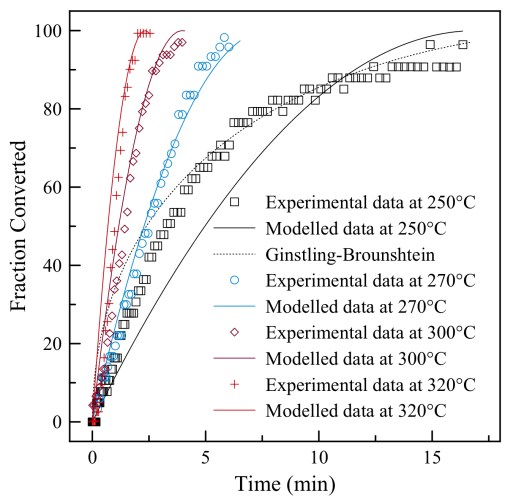

(b)

Figure 11: Dehydrogenation kinetics of the $\mathrm{Mg} / \mathrm{Cr}$ sample showing a) the linearised experimental data and $\mathrm{b}$ ) the experimental data and the modelled data derived from the $\mathrm{CV}$ model with $x=2$ at $250^{\circ} \mathrm{C}, 270^{\circ} \mathrm{C}, 300^{\circ} \mathrm{C}$ and $320^{\circ} \mathrm{C}$

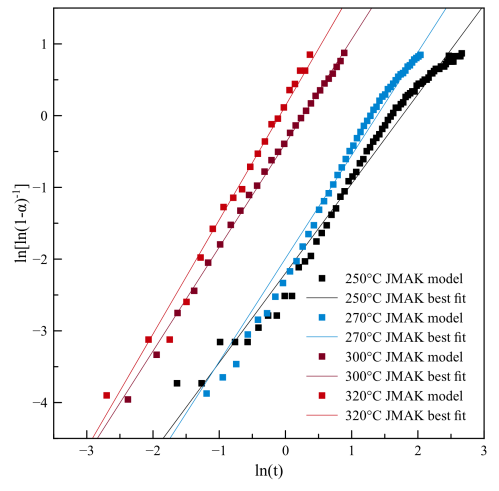

(a)

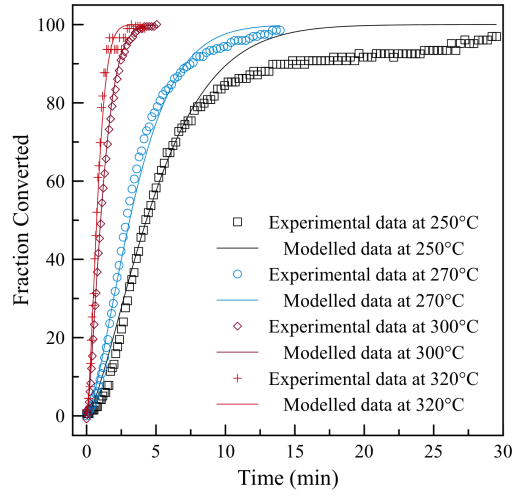

(b)

Figure 12: Dehydrogenation kinetics of the $\mathrm{Mg} / \mathrm{V}$ sample showing a) the linearised experimental data and $b$ ) the experimental data and the data derived from the JMAK model at $250^{\circ} \mathrm{C}, 270^{\circ} \mathrm{C}, 300^{\circ} \mathrm{C}$ and $320^{\circ} \mathrm{C}$

\section{Discussion}

The reversible capacity of up to $6.1 \mathrm{wt} \%$ measured for the $\mathrm{Mg} / \mathrm{Cr}$ sample, in combination with the fast dehydrogenation kinetics at temperatures as low as $250^{\circ} \mathrm{C}$ and the cycling stability over the 60 cycles that the sample was subjected to, are comparable to some of the high-performance, transition metal- and transition metal oxide-catalysed, 


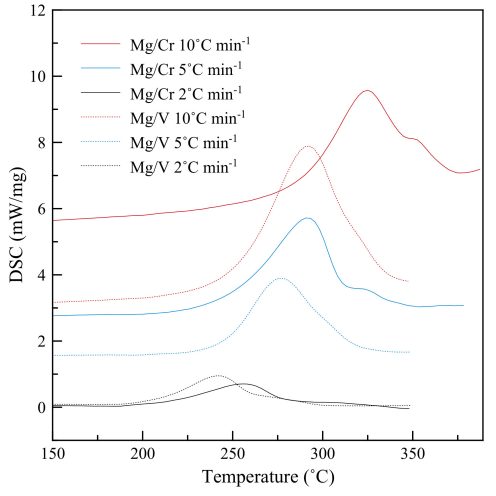

(a)

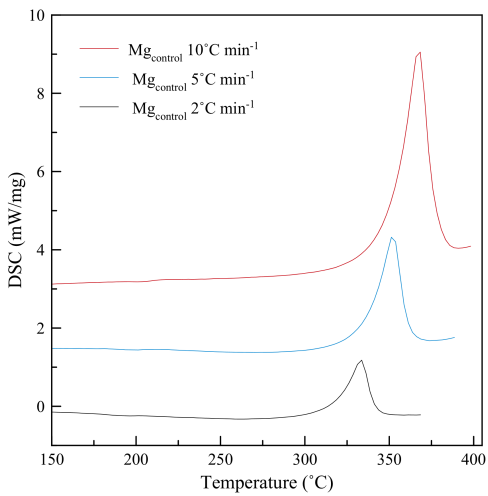

(b)

Figure 13: DSC plots measure for a) the $\mathrm{Mg} / \mathrm{Cr}$ and $\mathrm{Mg} / \mathrm{V}$ and b) the $\mathrm{Mg}_{\text {control }}$ samples at heating rates of 2,5 , and $10^{\circ} \mathrm{C} \mathrm{min}-1$

\begin{tabular}{lc} 
Sample & $\mathrm{E}_{a}\left(\mathrm{~kJ} \mathrm{~mol}^{-1}\right)$ \\
\hline $\mathrm{Mg} / \mathrm{Cr}$ & $65.7 \pm 2.5$ \\
$\mathrm{Mg} / \mathrm{V}$ & $67.6 \pm 1.2$ \\
$\mathrm{Mg}_{\text {control }}$ & $141.6 \pm 3.2$ \\
$\mathrm{MgH}_{2}$ & $147.7 \pm 6.0$
\end{tabular}

Table 3: Table showing the activation energies of the three samples' dehydrogenation reaction derived from Kissinger plots

\begin{tabular}{lcc} 
Sample & \multicolumn{2}{c}{ Gravimetric Capacity (wt\%) } \\
& PCI & TGA \\
\hline $\mathrm{Mg} / \mathrm{Cr}$ & $6.1 \pm 0.3$ & $5.7 \pm 0.1$ \\
$\mathrm{Mg} / \mathrm{V}$ & $5.4 \pm 0.3$ & $5.2 \pm 0.1$ \\
$\mathrm{Mg}_{\text {control }}$ & $5.4 \pm 0.2$ & $5.1 \pm 0.1$
\end{tabular}

Table 4: Table comparing the materials' capacities measured by volumetric (PCI) and gravimetric (TGA) methods

magnesium-based hydrogen storage systems reported in the literature[13-16].

The structural characterisation of the thin film samples shows that, in all three cases coatings in the range of $2.5 \mu \mathrm{m}-2.74 \mu \mathrm{m}$ were fabricated. The TEM study on the two catalysed samples in their as-deposited state shows that the coatings are formed by 150 layers of magnesium which are separated by layers of chromium and vanadium for the $\mathrm{Mg} / \mathrm{Cr}$ and $\mathrm{Mg} / \mathrm{V}$ samples respectively. This nanostructuring is in itself highly consistent with no homogenisation of the materials at any point in the structure, confirmed by the EDX map shown in figure 4. Similarly, the microstructure of the coatings is 
non-coherent and the highly oriented HCP magnesium structure is repeatedly interrupted by the transition metal interlayers, as shown in figure $3 \mathrm{~d}$. The two magnesium layers produce lattice fringes from different groups of planes in TEM, indicative of a different rotational orientation, given that the XRD pattern suggests a strong preferred orientation in the $<001>$ direction.

This structural separation of the magnesium layers contradicts results reported for similar structures in the literature by Baldi et al. [17]. They report a level of structural coherence across several multilayers of magnesium and titanium, as well as a degree of homogenisation in the uppermost 6 layers of their thin film which was not observed in this work. Their coating consisted of only 20 multilayers of magnesium separated by interlayers of titanium. This might be explained by the similar, HCP crystal structure and lattice spacing of both $\mathrm{Mg}(002)$ and $\mathrm{Ti}(002)$ at $2.605 \AA$ and $2.341 \AA$ respectively which is not present for the BCC transition metal elements used in this work.

As discussed in previous work [7], the XRD pattern of the as-deposited multilayer coatings delivers a reliable estimate of the thickness of the individual magnesium layers. In this case the grain size of $17 \pm 3$ and $16 \pm 3 \mathrm{~nm}$, derived from the peak broadening of the $\operatorname{Mg}(002)$ and $\operatorname{Mg}(004)$ planes which are oriented in the growth direction of the thin film, match closely the values of $18 \pm 0.1$ and $17 \pm 0.1 \mathrm{~nm}$ measured by high-resolution TEM.

In the case of the $\mathrm{Mg}_{\text {control }}$ sample an average grain size of $50 \pm 3 \mathrm{~nm}$ was measured from the XRD peak broadening of the $\operatorname{Mg}(002)$ and $\operatorname{Mg}(004)$ planes of atoms. The diffraction pattern exhibits similar levels of orientation in the $<001>$ direction which suggests that the discontinuity of the magnesium crystal structure is caused by the inclusion of the transition metal interlayers in the $\mathrm{Mg} / \mathrm{Cr}$ and $\mathrm{Mg} / \mathrm{V}$ sample and not by the PVD process.

The highly oriented nanostructure observed for the catalysed multilayer samples is lost after 60 cycles of hydrogen cycling at up to $320^{\circ} \mathrm{C}$. Both the catalysed samples and the control sample undergo significant morphological changes during hydrogen cycling, transforming in their appearance from shiny, metallic films to grey, flakey powders. This change was measured also on a microstructural level, evident from the XRD study of the hydrogenated powders. In all samples the magnesium signal has given way to a strong diffraction pattern that matches database patterns of $\beta$-phase magnesium hydride whilst the palladium signal in all three samples has been replaced by diffraction peaks coming from an $\mathrm{Mg}_{6} \mathrm{Pd}$ alloy. This is despite the insertion of a layer of chromium $(\mathrm{Mg} / \mathrm{Cr})$ and vanadium $(\mathrm{Mg} / \mathrm{V})$ separating the palladium capping layers from the multilayers. Tan et al. [4] show how metallic layers are less effective than metal hydride layers in preventing $\mathrm{Mg}-\mathrm{Pd}$ alloy formation, and given the lower dehydrogenation enthalpies of $4 \mathrm{~kJ} \mathrm{~mol}^{-1} \mathrm{H}_{2}$ for chromium [18] and $40.1 \mathrm{~kJ} \mathrm{~mol}^{-1}$ $\mathrm{H}_{2}$ for vanadium [19] compared with magnesium hydride, these elements will be in a metallic state at equilibrium conditions for magnesium hydride, allowing the formation of $\mathrm{Mg}_{6} \mathrm{Pd}$.

The grain growth observed in the hydride phase across all three samples, compared with the grain size of the as-deposited thin films, was in the range of $16 \mathrm{~nm}$ to over 100 $\mathrm{nm}$. This is in agreement with ball-milled materials of similar composition. Dal Toè et al. [20] observed an increase in grain size from 5 to $120 \mathrm{~nm}$ during activation at $350^{\circ} \mathrm{C}$ for magnesium hydride ball milled with $1 \mathrm{wt} \%$ graphite. Similarly, Huhn et al. 
[21] observe an increase from 11 to $200 \mathrm{~nm}$ for a $\mathrm{Nb}_{2} \mathrm{O}_{5}$-catalysed magnesium hydride sample at temperatures above $300^{\circ} \mathrm{C}$. Similarly, grain growth in non-catalysed, ballmilled magnesium hydride has been observed by Paik et al. [22] from $32 \mathrm{~nm}$ to 422 $\mathrm{nm}$, consistent with the observations that were made for the $\mathrm{Mg}_{\text {control }}$ sample.

In the two catalysed samples, evidence was found for the emergence of crystalline chromium and vanadium catalyst phases after hydrogen cycling, replacing the amorphous transition metal layers that were observed by TEM in the multilayer coatings. This was further confirmed by TEM studies on the hydrogenated powders which showed clearly that both samples contained nano-crystalline transition metal phases producing both electron diffraction patterns and lattice fringes in high-resolution TEM, with dspacings matching database values of chromium and vanadium respectively. The composition of these dark, circular features was further verified by EDX, shown in figures 6 and 8 , which confirms that the dark, crystalline features observed in bright-field TEM produce X-ray signals characteristic of chromium and vanadium for the $\mathrm{Mg} / \mathrm{Cr}$ and $\mathrm{Mg} / \mathrm{V}$ samples respectively.

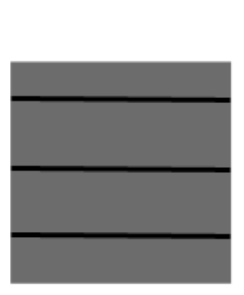

a)
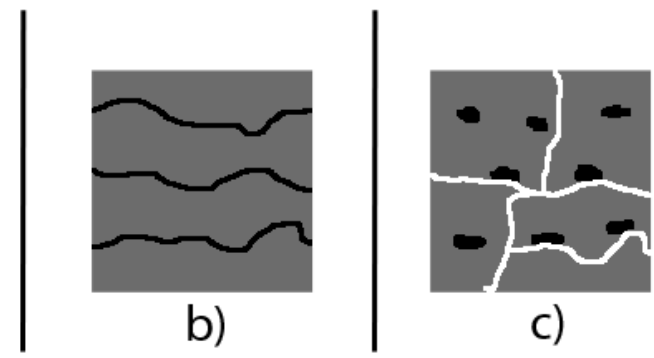

Figure 14: Schematic showing the suggested mechanism of the thin films' transformation and breakup with a) the as-deposited coating, b) deformed by hydrogen cycling and c) the transition metal layers forming nano-crystallites leading to the breaking up of the samples into a flaky powder

After hydrogen cycling, the thin film multilayers have broken up into grey, flakey powders, with particles as fine as those shown in the the TEM images in figures 5 and 7. This decrepitation of thin film materials has been observed for co-sputtered materials [4] as well as multilayered materials [23]. In the latter, the transformation is said to be caused by repeated expansion and contraction of the magnesium layers during hydrogen cycling. Figure 14 shows a schematic of the suggested mechanism where the as-deposited structure is first distorted by hydrogen cycling followed by the formation of nano-crystallites which leads to decrepitation of the thin film structure along some of the magnesium-transition metal interfaces. The volume expansion, recrystallisation and grain growth of the magnesium phase results in further decrepitation of the thin film flakes, breaking them up into smaller particles.

The hydrogen sorption studies show that clearly, both the catalysed samples and the control sample exhibit thermodynamics (in the range of $73.3-73.9 \mathrm{~kJ} \mathrm{~mol}^{-1} \mathrm{H}_{2}$ and $133.4-134.8 \mathrm{~J} \mathrm{~K}^{-1} \mathrm{~mol}^{-1} \mathrm{H}_{2}$ ) that are comparable with literature values for magnesium hydride $[24,25]$. 
The capacities of the thin film samples have been measured both by gravimetric and volumetric methods and both methods match within the quoted errors. Similarly, the kinetics of the thin film samples have been assessed both by calorimetric and volumetric methods and were found to be consistent across both measurement techniques. Table 5 compares the thin film samples' activation energies with a range of catalysed samples from the literature. The activation energy of between 65.7 and $69.7 \mathrm{~kJ} \mathrm{~mol}^{-1}$ for the $\mathrm{Mg} / \mathrm{Cr}$ sample and between 67.6 and $71.1 \mathrm{~kJ} \mathrm{~mol}^{-1}$ for the $\mathrm{Mg} / \mathrm{V}$ sample match literature values for materials of similar composition whilst the $\mathrm{Mg}_{\text {control }}$ sample's measured activation energy of between 141.6 and $142.9 \mathrm{~kJ} \mathrm{~mol}^{-1}$ matches literature values for magnesium hydride as well as the measured $147.7 \mathrm{~kJ} \mathrm{~mol}^{-1}$ for as-received magnesium hydride. This suggests that the processing conditions employed in producing the thin film multilayers has no impact on the hydrogen storage properties, and the reaction is improved purely by the microstructure and elemental composition of the catalysed materials.

\begin{tabular}{|c|c|c|}
\hline Composition & Activation energy & Reference \\
\hline $\mathrm{Mg} / \mathrm{TM}$ multilayer & $71.6 \mathrm{~kJ} \mathrm{~mol}^{-1}$ & [7] \\
\hline $\mathrm{MgH}_{2}+\mathrm{Ti}$ & $71.1 \mathrm{~kJ} \mathrm{~mol}^{-1}$ & [14] \\
\hline $\mathrm{MgH}_{2}+\mathrm{TiO}_{2}$ & $72 \mathrm{~kJ} \mathrm{~mol}^{-1}$ & [26] \\
\hline $\mathrm{MgH}_{2}+\mathrm{V}$ & $62.3 \mathrm{~kJ} \mathrm{~mol}^{-1}$ & [14] \\
\hline $\mathrm{MgH}_{2}+\mathrm{Mn}$ & $104.6 \mathrm{~kJ} \mathrm{~mol}^{-1}$ & [14] \\
\hline $\mathrm{MgH}_{2}+\mathrm{Fe}$ & $67.6 \mathrm{~kJ} \mathrm{~mol}^{-1}$ & [14] \\
\hline $\mathrm{MgH}_{2}+\mathrm{Ni}$ & $88.1 \mathrm{~kJ} \mathrm{~mol}^{-1}$ & [14] \\
\hline $\mathrm{MgH}_{2}+\mathrm{Nb}_{2} \mathrm{O}_{5}$ & $61 \mathrm{~kJ} \mathrm{~mol}^{-1}$ & [27] \\
\hline
\end{tabular}

Table 5: Comparison of catalysed $\mathrm{MgH}_{2}$ activation energies with the $\mathrm{Mg} / \mathrm{Tm}$ thin film

The reaction mechanisms of the two catalysed samples were investigated using modelling techniques. It was found that the $\mathrm{CV}_{n=2}$ model provided the best fit throughout the temperature range of between $250^{\circ} \mathrm{C}$ and $320^{\circ} \mathrm{C}$ for the $\mathrm{Mg} / \mathrm{Cr}$ sample whilst, for the same temperature range, the JMAK model provided the best fit for the kinetic data measured for the $\mathrm{Mg} / \mathrm{V}$ sample.

Figure 11a shows dehydrogenation data measured for the $\mathrm{Mg} / \mathrm{Cr}$ sample, linearised using the $\mathrm{CV}_{n=2}$ equation (equation 2). There is a linear correlation between the measured data except for the measurement at $250^{\circ} \mathrm{C}$. This can be explained by a change in reaction mechanism governed by diffusion. Figure $11 \mathrm{~b}$ compares the dehydrogenation data measured for the $\mathrm{Mg} / \mathrm{Cr}$ sample with data derived from the $\mathrm{CV}_{n=2}$ model for values of $k$ established from the linear regression lines through the linearised data. The graph also includes data modelled using the Ginstling-Brounshtein model [11] which takes into account diffusion as a rate-limiting step. This validates the hypothesis that at lower temperatures diffusion may take over from the $\mathrm{CV}$ model as the rate limiting step for the dehydrogenation reaction in the $\mathrm{Mg} / \mathrm{Cr}$ sample.

Figure 12a shows dehydrogenation data measured for the $\mathrm{Mg} / \mathrm{V}$ sample, linearised using the JMAK model (equation 1) which assumes random nucleation of new phases in the bulk [10]. From the linear regression line through the data for each temperature values of $n$ and $k$ were established, which were used to model the dehydrogenation 
reaction, and compare the modelled data with the measured data, as shown in figure 12b. A good match between the modelled and experimental data is evident, although at $250^{\circ} \mathrm{C}$, slowing of the experimental data compared with the model can be seen. This is likely to be a result of diffusion taking over from the JMAK model as the rate-limiting step for the reaction.

The main difference between the JMAK and CV models is the assumption in the $\mathrm{CV}$ model that nucleation is fast, and therefore negligible. The cause of the change in the rate-limiting mechanism of the reaction that is observed is likely to be the different catalyst used in the interlayer although it must be noted that the vanadium is a thicker interlayer than the chromium due to their different sputtering rates. Given the similar microstructure of the two materials, this might suggest that chromium is a more effective catalyst for the dehydrogenation reaction of magnesium hydride, despite claims by Zahiri et al. [28] that chromium is a poor catalyst in comparison with vanadium.

Unlike in other, similar multilayer systems that have been studied [23], the initial multilayer structure is lost during the structural evolution of the materials presented. The thin film materials studied do however demonstrate that despite this, multilayering produces materials with fast kinetics and stable nano structures comparable to those produced by ball milling.

\section{Conclusion}

Nanostructured multilayers of magnesium with interlayers of a chromium and vanadium as well as a non-catalysed magnesium control sample were produced by magnetronassisted physical vapour deposition in gram quantities to allow easier hydrogen cycling measurement and better comparison with bulk materials.

The coatings reversibly absorb up to $6.1 \mathrm{wt} \%$ of hydrogen with hydrogen storage properties comparable to materials of similar compositions, synthesised by mechanical methods which are more time intensive. Furthermore, PVD provides greater levels of control over the (nano-)structure of the resulting materials as well as the composition. Co-deposition and multilayering techniques add a further dimension which allows "tailoring" of structures beyond the capabilities of mechanical synthesis.

The multilayer materials presented in this work contain amorphous layers of transition metal elements, sandwiched between thin $(16-17 \mathrm{~nm})$ layers of crystalline magnesium. Upon hydrogen cycling these amorphous layers form nano-crystallites whilst the coatings break up into flakey powders with (in the case of the catalysed samples) a fine distribution the catalyst phase. These powders then exhibit stable hydrogen storage kinetics and capacities over the 60 cycles that the materials were subjected to.

\section{Acknowledgements}

Many thanks to Eminate Ltd. and especially to Dr Nick Botterill for access to the Teer Coatings PVD rig and to Dr Nigel Neate and Dr Mike Fay for their help with the $\mathrm{X}$-ray diffraction and electron microscopy studies. 


\section{Bibliography}

[1] Higuchi, K., Yamamoto, K., Kajioka, H., Toiyama, K., Honda, M., Orimo, $\mathrm{S}$., et al. Remarkable hydrogen storage properties in three-layered $\mathrm{Pd} / \mathrm{Mg} / \mathrm{Pd}$ thin films. Journal of Alloys and Compounds 2002;330:526-530.

[2] Krozer, A., Kasemo, B.. Hydrogen Uptake by Pd-Coated Mg - Absorption - Decomposition Isotherms and Uptake Kinetics. J Less-Common Met 1990;160(2):323-342.

[3] Baldi, A., Palmisano, V., Gonzalez-Silveira, M., Pivak, Y., Slaman, M., Schreuders, H., et al. Quasifree $\mathrm{Mg}-\mathrm{H}$ thin films. Appl Phys Lett 2009;95(7):071903.

[4] Tan, X., Harrower, C.T., Amirkhiz, B.S., Mitlin, D.. Nano-scale bi-layer Pd/Ta, $\mathrm{Pd} / \mathrm{Nb}, \mathrm{Pd} / \mathrm{Ti}$ and $\mathrm{Pd} / \mathrm{Fe}$ catalysts for hydrogen sorption in magnesium thin films. International Journal of Hydrogen Energy 2009;34(18):7741-7748.

[5] Ouyang, L.Z., Ye, S.Y., Dong, H.W., Zhu, M.. Effect of interfacial free energy on hydriding reaction of Mg-Ni thin films. Appl Phys Lett 2007;90(2):021917.

[6] Patel, N., Kale, A., Mosaner, P., Checchetto, R., Miotello, A., Das, G.. Deuterium thermal desorption from Ni-rich deuterated Mg thin films. Renewable Energy 2008;33(2):232-236.

[7] Fry, C.M.P., Grant, D.M., Walker, G.S.. Improved hydrogen cycling kinetics of nano-structured magnesium/transition metal multilayer thin films. International Journal of Hydrogen Energy 2013;38(2):982-990.

[8] Klug, H., Alexander, L.. X-Ray Diffraction Procedures. Mellon Institute of Science; 1974.

[9] Cullity, B.D., Stock, S.R.. Elements of X-ray Diffraction; vol. 3. Prentice hall Upper Saddle River, NJ; 2001.

[10] Kelton, K.F.. Analysis of crystallization kinetics. Materials Science and Engineering: A 1997;226:142-150.

[11] Khawam, A., Flanagan, D.R.. Solid-State Kinetic Models: Basics and Mathematical Fundamentals. J Phys Chem B 2006;110(35):17315-17328.

[12] Kissinger, H.E.. Variation of peak temperature with heating rate in differential thermal analysis. Journal of Research of the National Bureau of Standards 1956;57(4):217-221.

[13] Hanada, N., Ichikawa, T., Hino, S., Fujii, H.. Remarkable improvement of hydrogen sorption kinetics in magnesium catalyzed with Nb2O5. Journal of Alloys and Compounds 2006;420(1-2):46-49. 
[14] Liang, G., Huot, J., Boily, S., Van Neste, A., Schulz, R.. Catalytic effect of transition metals on hydrogen sorption in nanocrystalline ball milled $\mathrm{MgH}_{2}$ $\mathrm{Tm}(\mathrm{Tm}=\mathrm{Ti}, \mathrm{V}, \mathrm{Mn}, \mathrm{Fe}$ and $\mathrm{Ni})$ systems. Journal of Alloys and Compounds 1999;292(1-2):247-252.

[15] Jung, K.S., Lee, E.Y., Lee, K.S.. Catalytic effects of metal oxide on hydrogen absorption of magnesium metal hydride. Journal of Alloys and Compounds 2006;421(1-2):179-184.

[16] Dehouche, Z., Klassen, T., Oelerich, W., Goyette, J., Bose, T., Schulz, R.. Cycling and thermal stability of nanostructured $\mathrm{MgH}_{2}-\mathrm{Cr}_{2} \mathrm{O}_{3}$ composite for hydrogen storage. Journal of Alloys and Compounds 2002;347(1-2):319-323.

[17] Baldi, A., Pálsson, G., Gonzalez-Silveira, M., Schreuders, H., Slaman, M., Rector, J.H., et al. $\mathrm{Mg} / \mathrm{Ti}$ multilayers: Structural and hydrogen absorption properties. Phys Rev B 2010;81(22):224203.

[18] Zahiri, B., Amirkhiz, B.S., Mitlin, D.. Hydrogen storage cycling of $\mathrm{MgH}_{2}$ thin film nanocomposites catalyzed by bimetallic Cr Ti. Appl Phys Lett 2010;97(8):083106.

[19] US DOE, . Targets for Onboard Hydrogen Storage Systems for Light-Duty Vehicles $2009 ;: 1-22$.

[20] Dal Toè, S., Lo Russo, S., Maddalena, A., Principi, G., Saber, A., Sartori, S., et al. Hydrogen desorption from magnesium hydride-graphite nanocomposites produced by ball milling. Materials Science and Engineering B 2004;108(12):24-27.

[21] Huhn, P.A., Dornheim, M., Klassen, T., Bormann, R.. Thermal stability of nanocrystalline magnesium for hydrogen storage. Journal of Alloys and Compounds 2005;404-406:499-502.

[22] Paik, B., Walton, A., Mann, V., Book, D., Jones, I.P., Harris, I.R.. Microstructure of ball milled $\mathrm{MgH}_{2}$ powders upon hydrogen cycling: An electron microscopy study. International Journal of Hydrogen Energy 2010;35(17):90129020.

[23] Kalisvaart, W.P., Kubis, A., Danaie, M., Amirkhiz, B.S., Mitlin, D.. Microstructural evolution during hydrogen sorption cycling of Mg-FeTi nanolayered composites. Acta Materialia 2011;59(5):2083-2095.

[24] Klose, W., Stuke, V.. Investigation of the Thermodynamic-Equilibrium in the Hydrogen-Magnesium-Magnesium Hydride System. International Journal of Hydrogen Energy 1995;20(4):309-316.

[25] Bogdanovic, B., Bohmhammel, K., Christ, B., Reiser, A., Schlichte, K., Vehlen, R., et al. Thermodynamic investigation of the magnesium-hydrogen system. Journal of Alloys and Compounds 1999;282:84-92. 
[26] Croston, D.L., Grant, D.M., Walker, G.S.. The catalytic effect of titanium oxide based additives on the dehydrogenation and hydrogenation of milled $\mathrm{MgH}_{2}$. Journal of Alloys and Compounds 2010;492(1-2):251-258.

[27] Barkhordarian, G., Klassen, T., Bormann, R.. Effect of $\mathrm{Nb}_{2} \mathrm{O}_{5}$ content on hydrogen reaction kinetics of Mg. Journal of Alloys and Compounds 2004;364(12):242-246.

[28] Zahiri, B., Danaie, M., Tan, X., Amirkhiz, B.S., Botton, G.A., Mitlin, D.. Stable Hydrogen Storage Cycling in Magnesium Hydride, in the Range of Room Temperature to $300^{\circ} \mathrm{C}$, Achieved Using a New Bimetallic Cr-V Nanoscale Catalyst. J Phys Chem C 2012;:3188-3199. 